\title{
Electron Microscopy Characterization of Aluminum Alloy - Fly Ash Composites
}

\author{
D. P. Robertson ${ }^{*}$, M. Gajdardziska-Josifovska*, J. K. Kim ${ }^{* *}$, R. Q. Guo ${ }^{* *}$, and P. K. Rohatgi** \\ *Department of Physics, ${ }^{* *}$ Materials Department, University of Wisconsin - Milwaukee, P.O. Box \\ 413, Milwaukee, WI 53201.
}

There is an increasing interest in metal matrix composites where the reinforcements are lower in cost and density than the matrix; an example is the possible use of solid or hollow spherical fly ash particles as fillers or reinforcements in aluminum matrix composites. We have recently developed aluminum-fly ash composites with low density, low cost, and improved hardness and wear resistance $[1,2]$. Here we summarize the results of structure investigations employing a combination of optical metallography and transmission electron microscopy (TEM) methods [3].

The aluminum silicon alloy (A356) was used as the matrix alloy. Stir casting was used to form the aluminum-matrix composite containing five weight percentages of fly ash spheres. The as -cast specimens of A356 and A356 -fly ash composites were heated at $538^{\circ} \mathrm{C}$ for 3 hours in $\mathrm{N} 2$ environment and quenched in hot water. Studies focused on the comparison of as -cast specimens of A356 and A356 -fly ash composites, and specimen s of each subjected to a heat treatment. Metallography studies (not shown here) were performed with Olympus optical microscopes after standard polishing procedures and during TEM sample preparation. The main challenge was to retain fly ash particles and o btain fly ash/matrix boundaries in the thinned regions. To this end optical microscopy was used to select promising regions for dimpling and grazing incidence ion milling. A $300 \mathrm{keV}$ Hitachi H9000NAR electron microscope, equipped with a Gatan CCD and a Noran EDS, was used for bright field imaging, selected area diffraction (SAD) and energy dispersive $\mathrm{X}$-ray spectroscopy analysis.

Low magnification TEM imaging, just like optical microscopy, reveals the two main types of inclusion that exist in the as cast alloy: Fig. 1 shows single crystal Si polyhedrons that precipitate from the alloy during casting; Fig. 2 shows a cluster of polycrystalline fly ash hollow spheres that are added to the alloy. Higher magnification images of interfaces between the $\mathrm{Al}$ matrix and the $\mathrm{Si}$ interdendritic phase reveal a higher dislocation density in the as-cast A356-fly ash composites (Fig. 3) compared to the heat treated base A356 alloy (Fig. 5). In addition, the dislocation density in the aluminum matrix near the $\mathrm{Si}$ phase is higher than that in the aluminum matrix away from the $\mathrm{Si}$ phase in both cases [3]. This observation suggests that the Si precipitates, which are harder and have a lower expansion coefficient than the aluminum matrix, enhance the generation of dislocations during cooling of the composite containing fly ash particles. In comparison with $\mathrm{Si}$, the metal matrix around the fly-ash particle displays a mottled contrast without obvious dislocation lines or loops both in the as-cast (Fig. 4) and the heat-treated composite (Fig.6). Many nano-sized particles have precipitated during heat treatment in areas near the fly ash particle. In contrast, there are no visible fine particles near Si phases in the base alloy subjected to the same heat treatments. The EDX analysis indicates that $\mathrm{Mg}$, added as a wetting agent to aluminum melt during the addition of fly ash particles, appears to segregate at the matrix/fly-ash interface [3]. The microscopy characterization provides an explanation for the mechanical properties of these composites: They have a higher ascast hardness than the base alloy, but the addition of fly ash particles does not lead to significant acceleration in the aging kinetics. [3]. 
[1] P.K. Rohatgi, JOM, 1994, Nov., pp. 55-58.

[2] R. Guo et al., Trans. Am. Foundrymen's Soc., 1996, vol. 104, pp. 1097-1101.

[3] P.K. Rohatgi et al., Metall. Matter. Trans. A, 2002, vol. 33A in press.
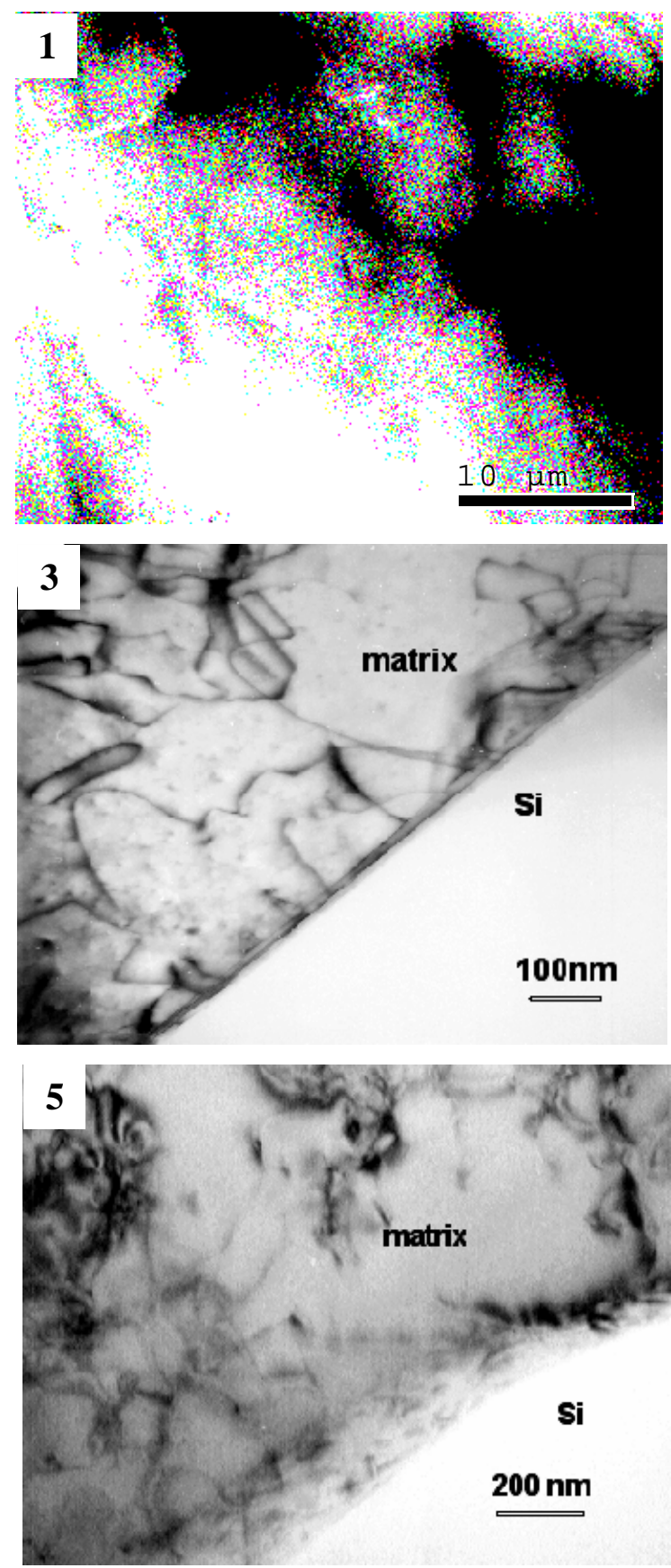
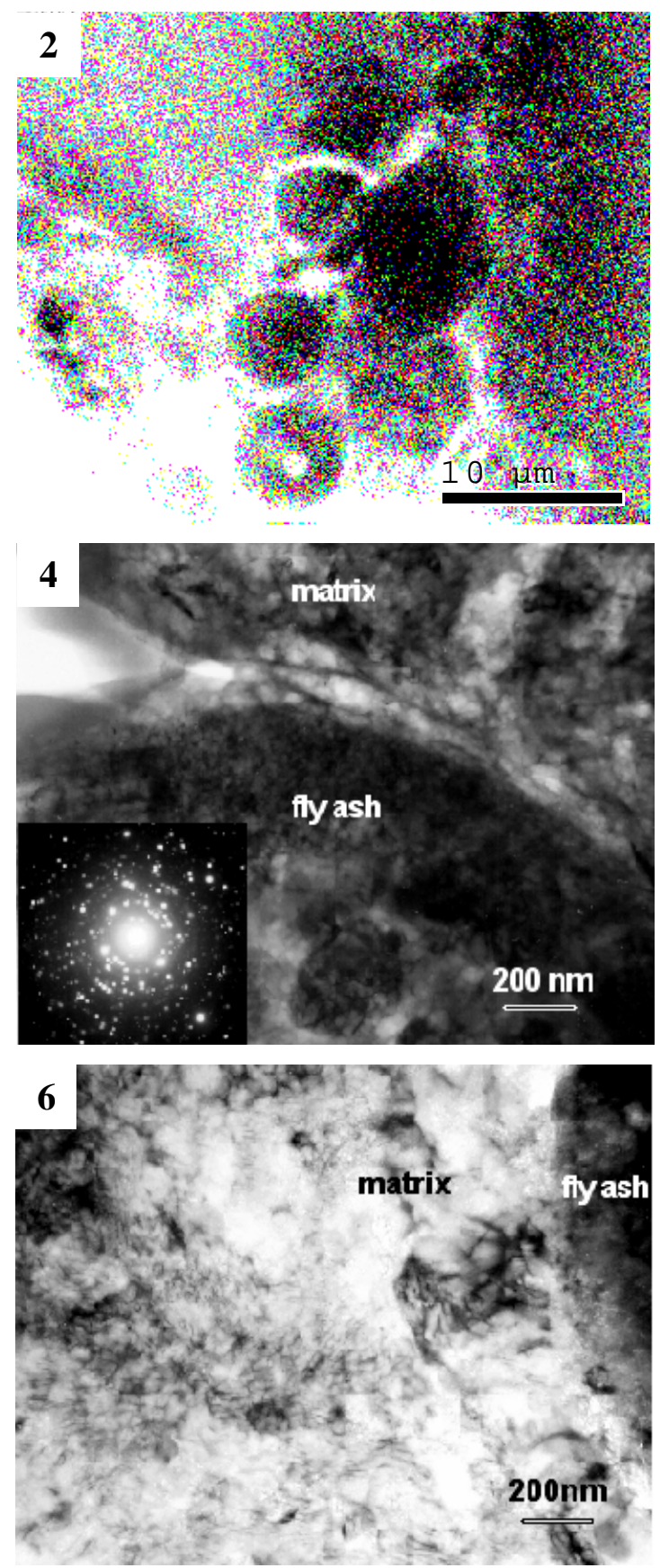

Fig. 1 BF-TEM image of Si inclusions in as-cast aluminum A356-fly ash composite.

Fig. 2 BF-TEM image of fly-ash inclusions in as-cast aluminum A356-fly ash composite.

Fig. 3 BF-TEM image of interface between Si precipitate and as-cast Al matrix.

Fig. 4 BF-TEM image of interface between fly-ash inclusion and as-cast Al matrix.

Fig. 5 BF-TEM image of interface between heat treated $\mathrm{Si}$ precipitate and Al matrix.

Fig. 6 BF-TEM image of interface between heat treated fly-ash inclusion and Al matrix. 